\title{
Formulation and Evaluation of Fast Dissolving Oral Film of Imipramine
}

\author{
Rozhan A. Muhammed*, Huner K. Omer \\ Department of Pharmaceutics, College of Pharmacy, Hawler Medical University, Erbil, Kurdistan Region, Iraq
}

\section{${ }^{*}$ Corresponding author: \\ Rozhan A. Muhammed, \\ Department of \\ Pharmaceutics, College of Pharmacy, Hawler Medical University, Erbil, Kurdistan Region, Iraq. E-mail: rojan. arif@tiu.edu.iq}

Received: 10 January 2019

Accepted: 16 May 2019

Published: 30 June 2020

DOI

10.25156/pti.v10n1y2020.pp182-188

\section{A B S T R A C T}

Fast dissolving oral film is a new emerging solid dosage form in which it consists of thin strips administered orally and dissolved in mouth within the seconds. The study is purposed to use water soluble polymers to provide rapid film disintegration as the films are hydrated in mouth and to find the best polymer type and its concentration to formulate the drug. Initially, placebo films were prepared using solvent casting method then two formulations from the prepared placebo films were selected to formulate imipramine. The excipients were dissolved in water then the drug solution was prepared by dissolving $150 \mathrm{mg}$ of drug in $5 \mathrm{ml}$ of water then mixed with the excipients and they were mixed gently and casted in disposable Petri dishes and left for $24 \mathrm{~h}$ in oven to provide film dryness. Then, the films removed from Petri dish and cut to $2 \mathrm{~cm} \times 2 \mathrm{~cm}$ small strips. Then, the tests were performed. Successful films were prepared by $45 \%$ hydroxypropyl methyl cellulose (HPMC) and $50 \%$ sodium carboxymethyl cellulose ( $\mathrm{NaCMC}$ ). The films were smooth, easily removed from Petri dish without tearing and homogenous. The thin films were mechanically stable that they could be handled without breaking due to their good folding endurance which was more than 400 . The $\mathrm{pH}$ of the films was accepted since they were around saliva $\mathrm{pH}$ (5.3-6.9). The films disintegration time was $<60$ min since water-soluble polymers were used and this property provided rapid drug release from the formulation in which it was 15-20 min for both of the drug-containing films, while dissolution time for the imipramine conventional tablet was about $60 \mathrm{~min}$. Imipramine can be formulated as a new dosage form (fast dissolving film) using $45 \% \mathrm{HPMC}$ and $50 \% \mathrm{NaCMC}$ as polymer using solvent casting method to ease the drug administration for psychotic and pediatric patients since no water is required for this solid dosage for administration.

Keywords: FDOF, Hydroxypropyl methyl cellulose, Plasticizer, Polymer, Sodium carboxymethyl cellulose

\section{INTRODUCTION}

Orally fast dissolving films are new drug delivery system that consists of thin oral strips (solid dosage form) that dissolve in oral mucosa within seconds as it comes in contact with patient's saliva, the dosage form is administered easily by placing the strip or the film on the tongue (Bala et al., 2013). The film disintegrates rapidly as it gets wet by saliva without water administration to release the drug to the oral cavity, this route can be applied for local and systematic drug application (Panda et al., 2012).

Fast dissolving oral delivery system was first invented in the 1970s to overcome the swallowing problems of tablets and capsules by pediatric and elderly patients, but buccal route drug delivery becomes very important in recent years and increased patient acceptance and resulted in developing safer and newer drug delivery system and these are originated due to histology of oral mucosa (Dinge and Nagarsenker, 2008).
The most important excipients that must be present in the fast dissolving oral films formulation includes polymers, plasticizers, sweetening agent, stabilizing agent, saliva-stimulating agent, permeation enhancers, coloring agent, flavoring agent, superdisintegrants, and emulsifying agent and these excipients should be safe and non-toxic (Juluru, 2013).

Imipramine is tricyclic antidepressant which is sold under brand name Tofranil. It has been used for treating of depression that is associated with agitation and anxiety, it is also used for the treatment of nocturnal enuresis since imipramine shortens the delta wave stage sleep where bed wetting occurs. Since imipramine structure is similar to the structure of some muscle relaxants, so it has analgesic effect too (Jadhav et al., 2014).

This study aim to find the best polymer type to formulate film which have acceptable physical property (thickness and elasticity) to with stand handling, and its concentration 
used to formulate imipramine as fast dissolving oral film, then determine disintegration time for the films and drug release profile.

\section{MATERIALS AND METHODS}

\section{Materials and Instruments}

Pure imipramine hydrochloride powder was purchased from Apollo Healthcare, Singapore. Hydroxypropyl methyl cellulose k15 (HPMC), sodium carboxymethyl cellulose (NaCMC), polyvinylpyrrolidone (PVP k30) used as polymer, propylene glycol (PG) as plasticizer all were gifted from Awamedica drug industry, Iraq. Citric acid (as saliva stimulating agent), hydrochloric acid, and sodium saccharine (as sweetening agent) were provided by College of Pharmacy, Hawler Medical University. Distilled water was used through the study.

Instruments used are electrical melting point apparatus (Stuart, Copley Scientific, UK), analytical balance (Sartorius [BP211S], Germany), pH meter (Hanna Instrument, Italy), dissolution apparatus (Pharma test, PT-DT7, Germany), ultraviolet (UV) spectrophotometer (Analytik Jena Specord 40, Germany), magnetic stirrer (Copley Scientific, UK), magnetic hot plate (HC5O2 BIBBY, UK), Fourier transformation infrared (FTIR) spectrophotometer (Shimadzu Scientific Instruments, Japan), oven Memmert BE500 (Rostfrei, Schwach, Germany), and digital Vernier caliper (Maxwell Shanghai).

\section{Method}

\section{Formulation of the film}

Solvent casting method was used to formulate imipramine as fast dissolving oral film. The excipients were weighed accurately and dissolved in $25 \mathrm{ml}$ of water, then the drug was dissolved in $5 \mathrm{ml}$ of DW and mixed with the excipient solution. The mixture was mixed gently using magnetic stirrer for $3 \mathrm{~h}$ to avoid bubble formation. When viscous clear solution was formed, it was poured into a disposable Petri dish and put in oven overnight to evaporate the water and dry the solution. The film was removed gently from the Petri dish and cut into small pieces $(2 \mathrm{~cm} \times 2 \mathrm{~cm})$.

Three different concentrations for each polymer were used in this study $(40 \%, 45 \%$, and $50 \%)$. The amount of other excipients used in the experiment is tabulated in Table 1.

Nine placebo formulations were prepared from the excipients using different polymer concentration, as shown in Table 2. The best two formulas F2 and F9 were selected to formulate the fast dissolving oral film of imipramine [Tables 3 and 4] (Raju et al., 2011).

\section{Determination of pure imipramine melting point}

Capillary tube method was used to measure the melting point of imipramine. Small amount of imipramine powder was placed in a closed end capillary tube and placed in melting point apparatus. The temperature was increased gradually with close observation to detect the temperature at which the powder melts completely. The temperature at which the powder melts is recorded as melting point (Jadhav et al., 2014).

\section{Determination the $\lambda$ max of imipramine}

Imipramine solution with a concentration of $100 \mu \mathrm{g} / \mathrm{ml}$ in $0.1 \mathrm{~N} \mathrm{HCl}$ was prepared. The sample was scanned by UV

Table 1: Percentage concentration of the ingredients in the
film formulation
\begin{tabular}{|lc}
\hline Compound & $\% w / w$ \\
\hline Polymer & $40,45,50$ \\
Plasticizer & 15 \\
Sodium saccharin & 5 \\
Citric acid & 5 \\
Mannitol & qs.
\end{tabular}

Table 2: Placebo formulations that are prepared in the study

\begin{tabular}{lccccccccc|}
\hline Ingredients & F1 & F2 & F3 & F4 & F5 & F6 & F7 & F8 & F9 \\
\hline HPMC k15 (\%) & 40 & 45 & 50 & - & - & - & - & - & - \\
PVP k30 (\%) & - & - & - & 40 & 45 & 50 & - & - & - \\
NaCMC (\%) & - & - & - & - & - & - & 40 & 45 & 50 \\
Citric acid (\%) & 5 & 5 & 5 & 5 & 5 & 5 & 5 & 5 & 5 \\
PG (\%) & 15 & 15 & 15 & 15 & 15 & 15 & 15 & 15 & 15 \\
Sodium saccharine (\%) & 5 & 5 & 5 & 5 & 5 & 5 & 5 & 5 & 5 \\
Mannitol & q.s & q.s & q.s & q.s & q.s & q.s & q.s & q.s & q.s \\
Water (ml) & 30 & 30 & 30 & 30 & 30 & 30 & 30 & 30 & 30
\end{tabular}

HPMC: Hydroxypropyl methyl cellulose, NaCMC: Sodium carboxymethyl cellulose, PVP: Polyvinylpyrrolidone, PG: Propylene glycol

Table 3: Composition of imipramine fast dissolving oral film in HPMC polymer

\begin{tabular}{lc}
\hline Ingredients & Amounts \\
\hline Imipramine & $10 \mathrm{mg}$ \\
HPMC k15 & $45 \%$ \\
Citric acid & $5 \%$ \\
PG & $15 \%$ \\
Sodium saccharine & $5 \%$ \\
Mannitol & q.s \\
Water & $30 \mathrm{ml}$ \\
\hline
\end{tabular}

HPMC: Hydroxypropyl methyl cellulose, PG: Propylene glycol

Table 4: Composition of imipramine fast dissolving oral film in NaCMC polymer

\begin{tabular}{lc} 
Ingredients & Amounts \\
\hline Imipramine & $10 \mathrm{mg}$ \\
NaCMC & $50 \%$ \\
Citric acid & $5 \%$ \\
PG & $15 \%$ \\
Sodium saccharine & $5 \%$ \\
Mannitol & q.s \\
Water & $25 \mathrm{ml}$ \\
\hline
\end{tabular}

NaCMC: Sodium carboxymethyl cellulose, PG: Propylene glycol 
spectrophotometer in the range of $200-400 \mathrm{~nm}$. Then, the $\lambda \max$ was obtained (Jadhav et al., 2014).

\section{Determination of calibration curve}

The calibration curve for imipramine was plotted by preparation of serial dilutions of the drug from the stock solution in $0.1 \mathrm{~N} \mathrm{HCl}$. The diluted samples were scanned by UV spectrophotometer at imipramine $\lambda$ max. The absorbance of diluted samples was recorded and used to plot versus concentration to get the standard calibration curve. Then, the regression equation was obtained (Prichard, 2003).

\section{Evaluation of the Films Visual inspection}

The prepared oral films (with and without imipramine) were evaluated for surface texture, peelability, transparency, homogeneity, and flexibility.

\section{Film thickness}

Digital Vernier caliper was used to measure the thickness of the films with and without drug. The films with air bubbles and tears were excluded from the analysis. Thickness was measured at five locations (four corners and center) then mean thickness was calculated (Desu et al., 2013).

\section{Folding endurance}

Folding endurance for all type of the films was performed manually by folding and unfolding the film at the same place. The number of the folding times of the film without breaking was recorded as folding endurance (Gholve et al., 2018).

\section{Surface $p H$ study}

$\mathrm{pH}$ meter was used to measure the surface $\mathrm{pH}$ of the films. The films of each type were wetted by distilled water, then the ends of electrode were in contact with the film surface to determine the $\mathrm{pH}$ of the prepared films (Koland et al., 2010).

\section{In vitro disintegration time of the films}

Modified disintegration method was used to determine the disintegration time of the films (with and without imipramine). To perform this, $5 \mathrm{ml}$ of water was added in a Petri dish, then the film was put in the center of the Petri dish. The time at which the film starts to disintegrate or break was recorded as disintegration time (Ali et al., 2016).

The tests below were performed for films containing drug only.

\section{FTIR}

The FTIR spectra of pure imipramine powder were compared with the spectra of the fast dissolving oral films containing drug to see if there is any drug change or interaction between the drug and the formulation excipients in the formulation.

\section{In vitro dissolution time}

USP paddle apparatus was used to determine the drug release profile of the drug for the formulations. A $900 \mathrm{ml}$ of $0.1 \mathrm{~N} \mathrm{HCl}$ at $37 \pm 0.5^{\circ} \mathrm{C}$ with a rotation speed of $50 \mathrm{rpm}$ was used as dissolution media. This test was also performed for commercially available imipramine tablet. The drug concentration in each sample was determined by spectrophotometric technique at $250 \mathrm{~nm}$ to obtain the amount of drug release in each formulation (Rao and Suryakar, 2011).

\section{RESULTS}

\section{Determination of Melting Point}

The measured melting point of pure imipramine was found to be $174^{\circ} \mathrm{C}$.

\section{Determination the $\lambda$ max of Imipramine}

Maximum absorbance was at $250 \mathrm{~nm}$, as shown in Figure 1.

\section{Calibration Curve Determination}

The calibration curve of imipramine in $0.1 \mathrm{~N} \mathrm{HCl}$ is shown in Figure 2. The curve shows linearity in concentration range of $5-19 \mu \mathrm{g} / \mathrm{ml}$ with correlation coefficient of 0.9996 .

\section{Evaluation of the Films}

Results of film evaluations are expressed as mean \pm SD and they are tabulated in Table 5.

\section{FTIR Spectroscopy}

The FTIR spectra of the pure imipramine and films containing imipramine are shown in Figures 3-5.

\section{In vitro Dissolution Time}

When the extent drug release for the three samples was compared, about $50 \%$ of drug was released from the films (45\% HPMC and 50\% NaCMC) to the dissolution medium during the first 5 min while it took about $25 \mathrm{~min}$ for $50 \%$ of active ingredient to be released from the commercially

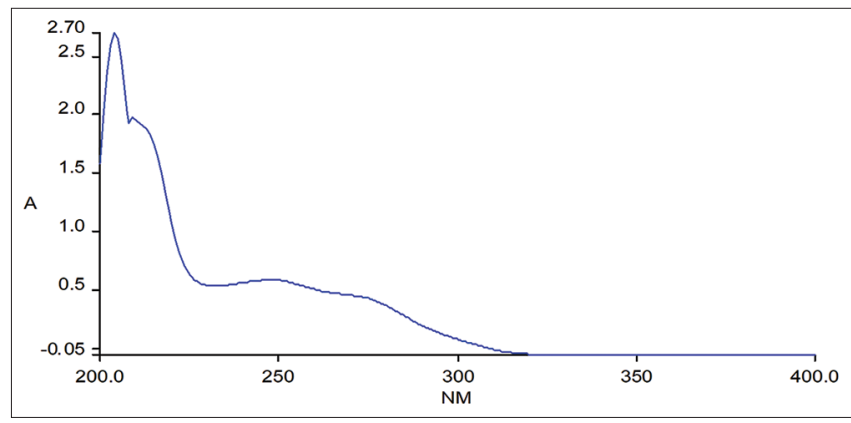

Figure 1: Ultraviolet spectra of imipramine in $0.1 \mathrm{~N} \mathrm{HCI}$ 
available tablet. The tests have been repeated 3 times, then the mean result was obtained. The details are shown in Figure 6.

\section{DISCUSSION}

For the imipramine formulation as fast dissolving film, three types of polymers and three different concentrations were

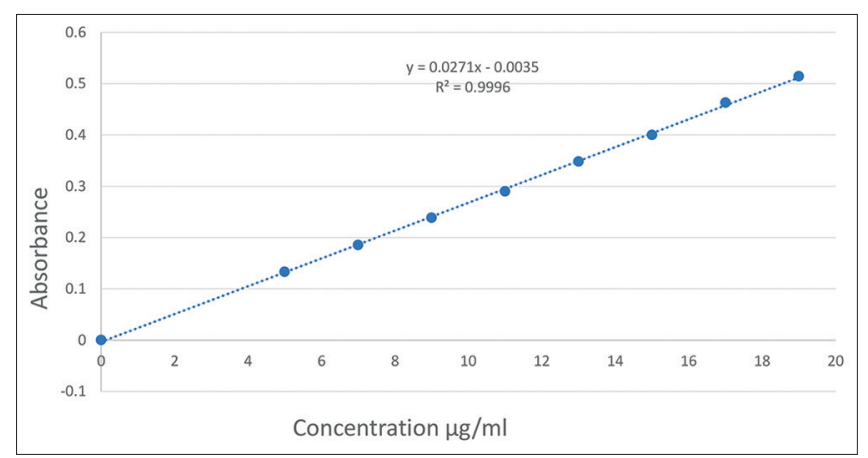

Figure 2: Calibration curve of imipramine in $0.1 \mathrm{~N} \mathrm{HCI}$ used for each, as shown in Table 1. The best two placebo films (F2 and F9) were selected according to their physical properties to formulate imipramine. Films prepared with $45 \%$ HPMC and 50\% NaCMC had good appearance, and not sticky with homogenous smooth texture. They were easily removed from the Petri dish [Table 5].

Evaluation tests were performed for the prepared films. The films had good folding endurance indicates their acceptable mechanical stability. Different studies showed that HPMC has good film forming capacity (ElMeshad and El Hagrasy, 2011; Kunte and Tandale, 2010). The selected polymers all are good film former depending on plasticizer type. The same polymer may not be good film former if another plasticizer type is used.

The films were very thin with thickness ranging from $0.04 \mathrm{~mm}$ to $0.09 \mathrm{~mm}$, thickness of film is directly concern with drug content uniformity, it is necessary to ascertain uniformity in the thickness of the films (Ghodake et al., 2013). Statistical analysis shows that there is a significant difference in the thickness of the formulations $(P<0.05)$

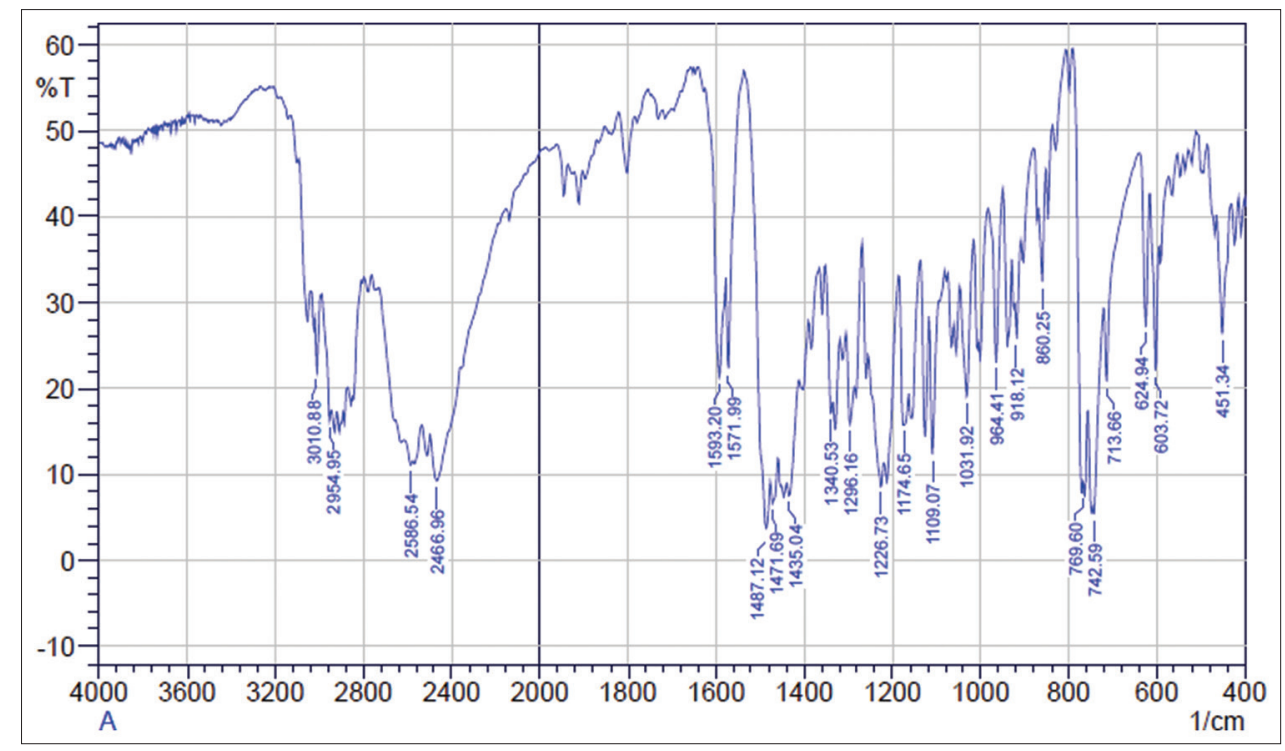

Figure 3: The spectra of pure imipramine powder

Table 5: Results of film evaluations, expressed as mean \pm SD

\begin{tabular}{|c|c|c|c|c|c|}
\hline Formula & Visual inspection & Thickness/mm & Folding endurance & Surface pH & D.T./S \\
\hline $\mathrm{F} 1$ & Peelable transparent & $0.04 \pm 0.007$ & $>300$ & $6.79 \pm 0.03$ & $20 \pm 0.707$ \\
\hline $\mathrm{F} 2$ & Peelable transparent & $0.06 \pm 0.007$ & $>300$ & $6.83 \pm 0.023$ & $21 \pm 0.707$ \\
\hline F3 & Peelable transparent & $0.07 \pm 0.007$ & $>300$ & $6.82 \pm 0.067$ & $23 \pm 0.707$ \\
\hline F4 & Sticky transparent & $0.04 \pm 0.0089$ & 120 & $6.58 \pm 0.05$ & $13 \pm 1$ \\
\hline F5 & Sticky transparent & $0.07 \pm 0.013$ & 140 & $6.84 \pm 0.032$ & $14 \pm 1.2$ \\
\hline F6 & Sticky milky transparent & $0.09 \pm 0.005$ & 190 & $6.72 \pm 0.016$ & $15.8 \pm 0.83$ \\
\hline F7 & Peelable milky transparent & $0.07 \pm 0.007$ & $>300$ & $6.84 \pm 0.027$ & $21 \pm 1.3$ \\
\hline F8 & Peelable milky transparent & $0.08 \pm 0.007$ & $>300$ & $6.9 \pm 0.039$ & $25 \pm 1.8$ \\
\hline F9 & Peelable transparent & $0.09 \pm 0.007$ & $>300$ & $7.1 \pm 0.048$ & $28 \pm 1.34$ \\
\hline F2+drug & Peelable transparent & $0.09 \pm 0.007$ & $>300$ & $5.3 \pm 0.19$ & $22 \pm 1.22$ \\
\hline F9+drug & Peelable milky transparent & $0.09 \pm 0.007$ & $>300$ & $5.43 \pm 0.083$ & $24 \pm 0.83$ \\
\hline
\end{tabular}




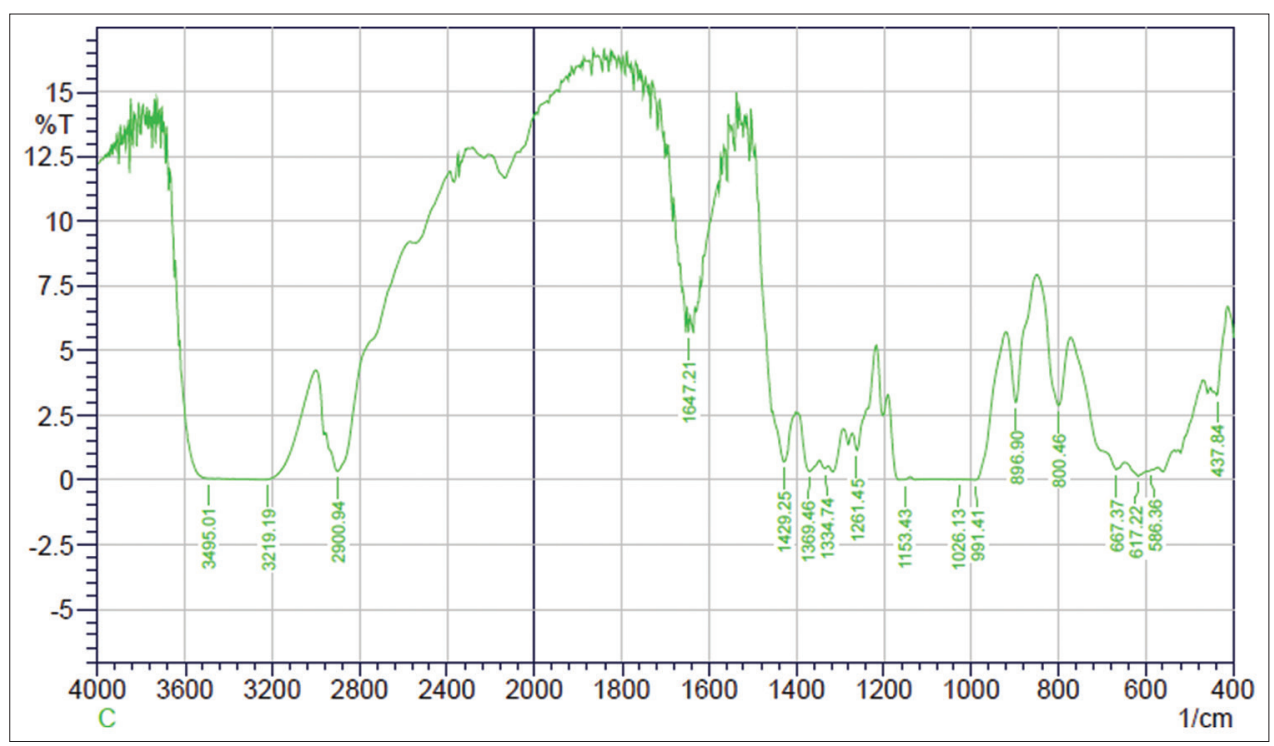

Figure 4: The spectra of the FDOF (drug formulated in $45 \%$ hydroxypropyl methyl cellulose)

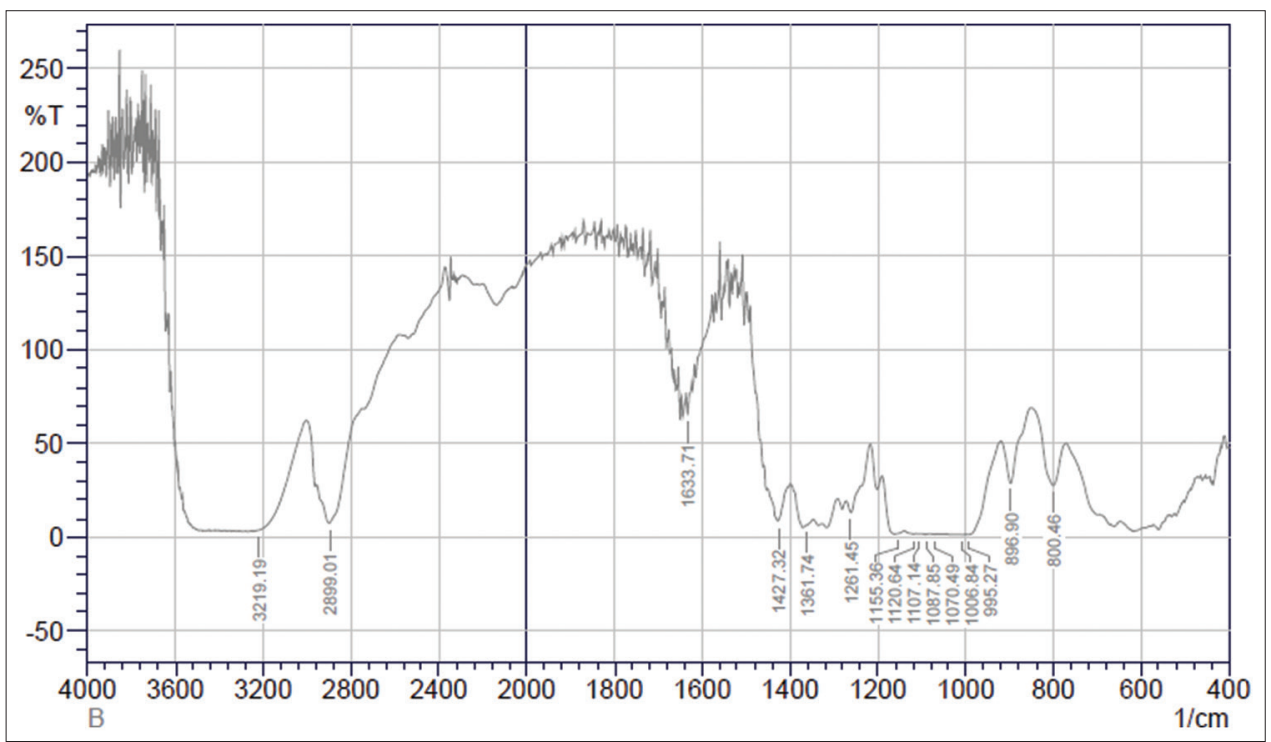

Figure 5: Spectra of the FDOF (drug formulated in $\mathbf{5 0 \%}$ sodium carboxymethyl cellulose)

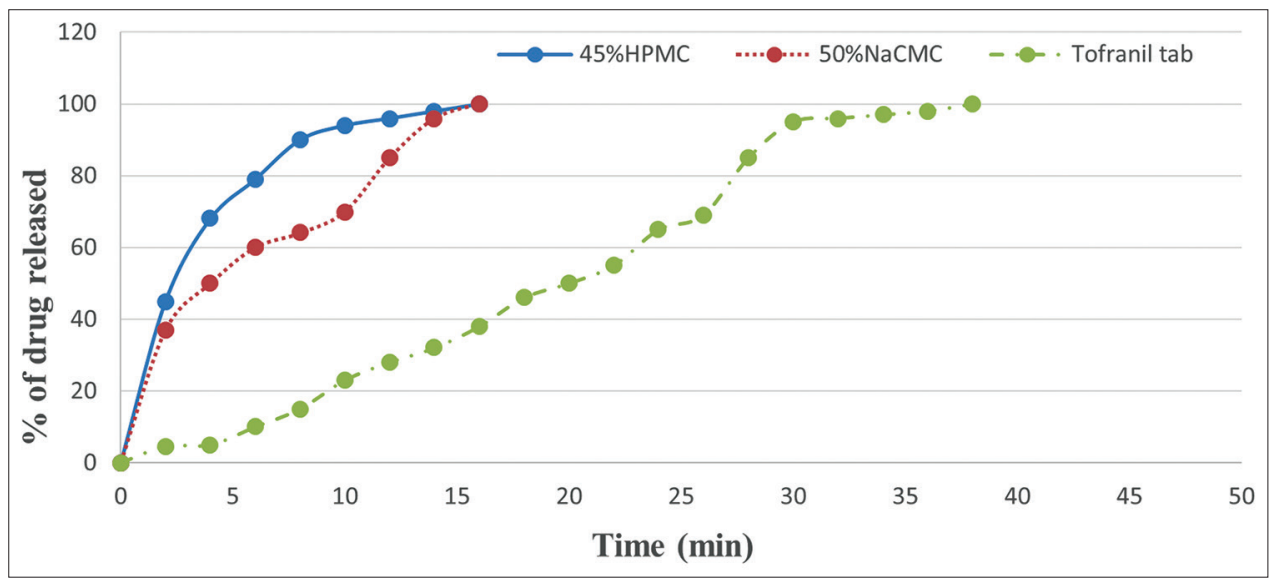

Figure 6: The drug release profile for the formulations of drug in $45 \%$ hydroxypropyl methyl cellulose, $50 \%$ sodium carboxymethyl cellulose, and for the conventional tablet (Tofranil $10 \mathrm{mg}$ ) 
since there is change in polymer concentrations. It is important for the prepared fast dissolving oral films to have acceptable folding endurance. Hence, they can withstand handling during packaging and they could be removed from the unit dose easily without breaking (Ketul et al., 2013).

According to a study done by Londhe and Umalkar, 2012, regarding the films with HPMC polymer, he noted that they had minimum folding endurance ( $53 \pm 2$ ) due to using of glycerol as plasticizer (Londhe and Umalkar, 2012).

While in our study, PG is used as plasticizer to get better folding endurance. The type of plasticizer had great effect on elasticity and peelability of the oral strip. Regarding the results of our study, there was no significance effect of polymer concentration on folding endurance $(P>0.05)$.

In this study, the prepared films with three different concentration of HPMC and $\mathrm{NaCMC}$ had higher folding endurance when compared to the films with PVP. The statistical analysis shows that there is no significant difference between the folding endurance of the films of all polymer types $(P>0.05)$.

The $\mathrm{pH}$ value of the films was measured too to make sure that they do not irritate the oral mucosa and the $\mathrm{pH}$ value was found to be around saliva $\mathrm{pH}$ (5.3-6.9). Alteration in $\mathrm{pH}$ of oral cavity is a matter of concern, especially when dosage form is intended to be taken by pediatrics. Minor change in $\mathrm{pH}$ of oral cavity can cause irritation which can lead to spitting of dosage form by the child (Singh, 2015).

Regarding disintegration time, all prepared films were broken in $<1$ min due to the using of water-soluble polymer and using water-soluble filler like mannitol. A study done by Ali et al. noted that the films containing HPMC disintegrate within 45-50 s when PEG 400 was used as plasticizer (Ali et al., 2016). While in our research, HPMC films disintegrate in a duration $<20$ min when formulated with PG as plasticizer.

The results of the FTIR spectra did not show any interaction between the drug and the excipients of the formulation.

Drug released profile was compared for both of the films containing imipramine and conventional tablet, as shown in Figure 6. About 100\% of the imipramine was released within 15-20 min while it took nearly $40 \mathrm{~min}$ for $100 \%$ drug release from the Tofranil conventional tablet.

\section{CONCLUSION}

Regarding the results of this study among the nine formulations, 45\% HPMC and 50\% NaCMC were the best polymer concentration to be used in the formulation of imipramine as fast dissolving oral film. Drug release profile for the films shows that $100 \%$ of drug could be released in a short duration since the films are disintegrated rapidly (with in few seconds) due to high water-soluble polymers used in the formulation.

\section{REFERENCES}

Ali, M., C. Vijenda, K. D. Sudheer and J. Krishnaveni. 2016. Formulation and evaluation of fast dissolving oral films of diazepam. J. Pharmacovigil. 4: 3.

Bala, R., P. Pawar, S. Khanna, and S. Arora. 2013. Orally dissolving strips: A new approach to oral drug delivery system. Int. J. Pharm. Investig. 3: 67-76.

Desu, P. K., B. Brahmaiah, A. Nagalakshmi, K. Neelima, S. Nama and C. Baburao. 2013. An overview on rapid dissolving films. Asian J. Pharm. Res. 3: 10.

Dinge, A. and M. Nagarsenker. 2008. Formulation and evaluation of fast dissolving films for delivery of triclosan to the oral cavity. AAPS PharmSciTech. 9: 349-356.

EIMeshad, A. N. and A. S. El Hagrasy. 2011. Characterization and optimization of orodispersible mosapride film formulations. AAPS PharmSciTech. 12: 1384-1392.

Ghodake, P. P., K. M. Karande, R. A. Osmani, R. R. Bhosale, R. Harkare, B. B. Kale. 2013. Mouth dissolving films: Innovative vehicle for oral drug delivery. Int. J. Pharma Bio Sci. 2: 41-47.

Gholve, S., S. Savalsure, O. Bhusnure, S. Surywanshi and M. Birajdar. 2018. Formulation and evaluation of oral fast dissolving sublingual film of propranolol $\mathrm{HCl}$. J. Res. Health Sci. 6: 65-72.

Jadhav, S. B., A. D. Mali, S. H. Rajeghadage and R. S. Bathe. 2014. Formulation and evaluation of immediate release tablets of imipramine hydrochloride. Int. J. Biomed. Adv. Res. 5: 559.

Juluru, N. S. 2013. Fast dissolving oral films: A review. Int. J. Adv. Pharm. Bio Chem. 2: 108-112.

Ketul, P., K. R. Patel, M. R. Patel and N. M. Patel. 2013. Fast dissolving films: A novel approach to oral drug delivery. Int. J. Pharm. 1: 13.

Koland, M., V. Sandeep, and N. Charyulu. 2010. Fast dissolving sublingual films of ondansetron hydrochloride: Effect of additives on in vitro drug release and mucosal permeation. J. Young Pharm. 2: 216-222.

Kunte, S. and P. Tandale. 2010. Fast dissolving strips: A novel approach for the delivery of verapamil. J. Pharm. Bioallied Sci. 2: 325 .

Londhe, V. Y. and K. B. Umalkar. 2012. Formulation development and evaluation of fast dissolving film of telmisartan. Indian J. Pharm. Sci. 74: 122-126.

Panda, B. P., N. S. Dey and M. E. B. Rao. 2012. Fast dissolving film as an effective orally disintegrating drug delivery system. Int. J. Pharm. Sci. 5(2): 9-24.

Prichard, L. 2003. Preparation of Calibration Curve. Valid Analytical Measurements, United States. p1-27.

Rajni, B., P. Pawar, S. Khanna and S. Arora. 2013. Orally dissolving strips: A new approach to oral drug delivery system. Int. J. 
Pharm. Investig. 3: 67-76.

Rao, N. G. R. and V. B. Suryakar. 2011. Design and development of mucoadhesive drug delivery system of montelukast sodium.
World J. Pharm. Pharm. Sci. 2(2): 491-497.

Singh, S. P. 2015. A review on fast dissolving formulation technologies. World J. Pharm. Pharm. Sci. 4: 574-585. 